\title{
Motor nerve conduction velocity in peroneal muscular atrophy: evidence for genetic heterogeneity
}

\author{
P. K. THOMAS AND D. B. CALNE
}

From the Royal Free, Royal National Orthopaedic, and Hammersmith Hospitals, London

SUMMARY Measurements of motor nerve conduction velocity are reported in 88 subjects from 20 families in which a clinical diagnosis of peroneal muscular atrophy had been made in the index cases. The values display a bimodal distribution. The majority of cases show a substantially reduced conduction velocity, a smaller group displaying velocities within the normal range or only slightly decreased. This difference was demonstrated to have a genetic basis.

The initial descriptions of peroneal muscular atrophy as a nosological entity were made simultaneously by Charcot and Marie (1886) and Tooth $(1886,1887)$, although isolated reports of similar cases had appeared earlier. The disorder is generally considered to be characterized by the onset in childhood or adolescence of a symmetrical atrophic weakness of the small muscles of the feet and of the peroneal and anterior tibial muscle group. This is frequently associated with a cavus or equinovarus foot deformity and clawing of the toes. The calf muscles are not affected until later and involvement of muscles above the knee is usually limited to the distal third of the thigh. The rate of progression is slow, but with advance of the disease, the small hand muscles may be affected, resulting in a claw-hand deformity. Later, the wrist and finger extensors may become weak. The ankle jerks are lost early, but there is a relative preservation of the knee and arm jerks. Sensation may be diminished in a distal distribution, but is usually not severely impaired. Some authors have accepted cases with severe distal sensory loss and perforating ulcers as instances of peroneal muscular atrophy (Halliday and Whiting, 1909; England and Denny-Brown, 1952). A mild associated ataxia has also been included as an occasional component of the syndrome, but more severe degrees of ataxia have generally led to such cases being classified as the Roussy-Lévy syndrome (Roussy and Lévy, 1926; 1934).

Despite early doubts by Marinesco (1894), the condition of hereditary hypertrophic polyneuropathy (Dejerine and Sottas, 1893) was soon sharply demarcated from peroneal muscular atrophy (Dejerine, 1896), and it came to be accepted that the disorders were separate entities. Yet there have been repeated descriptions of cases of peroneal muscular atrophy and hereditary hypertrophic neuropathy occurring in the same family (Pette, 1936; Van Leeuwen, 1943; François and Descamps, 1949; Luban, 1952), indicating that the demarcation on clinical grounds was not as simple as had been imagined. These disorders are rare and segregate clearly. It therefore seems reasonable to assume that despite the variety of clinical features, in any one family the affected individuals have in common the same genetic defect.

The pathology of peroneal muscular atrophy has been the subject of considerable debate and will be considered later. Definite conclusions have been hampered by a paucity of autopsy studies. England and Denny-Brown (1952) considered that the conflicting opinions could be divided into those that upheld a primarily spinal pathology as opposed to those that favoured a peripheral neuropathy. They themselves concluded that the disorder was likely to be a 'radicular neuropathy'.

Early reports of measurements of motor nerve conduction velocity in peroneal muscular atrophy (Henriksen, 1956; Gilliatt and Thomas, 1957) recorded gross reductions in velocity, and this was confirmed by Christie (1961), Amick and 
Lemmi (1963), Dyck et al. (1963), Earl and Johnson (1963), Blom et al. (1964) and later workers. Subsequent observations on sporadic cases by one of the present authors indicated that in clinically similar cases, conduction velocity could either be within normal limits or only slightly reduced, and that these differences did not depend upon the stage of the disease. It was therefore decided to embark upon a systematic study of the changes in nerve conduction in families with peroneal muscular atrophy in order to establish whether the type of alteration was consistent within families. After the investigation had been initiated, the important study by Dyck and Lambert (1968a,b) appeared, in which comparable results to those recorded here were obtained. A preliminary communication on the findings of the present investigation has already been made (Thomas and Calne, 1971).

\section{METHODS}

The investigation was performed on all cases of peroneal muscular atrophy with a history of familial involvement referred to one of us (PKT) over a four year period (1966-70). Most cases were seen in the neurological clinic at the Royal National Orthopaedic Hospital. The criteria adopted for diagnosis were those given above, except that some cases showed a more generalized depression of the tendon reflexes.

All accessible relatives were examined by ourselves, and nerve conduction studies were performed on all the index cases and on all relatives who consented, whether or not they were clinically affected.

Motor nerve conduction velocity was measured in the median and peroneal nerves, recording from the abductor pollicis brevis and extensor digitorum brevis muscles respectively, employing the technique described by Thomas et al. (1959). Skin temperature over the distal part of the limb at the time of recording, measured with a thermistor (Light Laboratories),

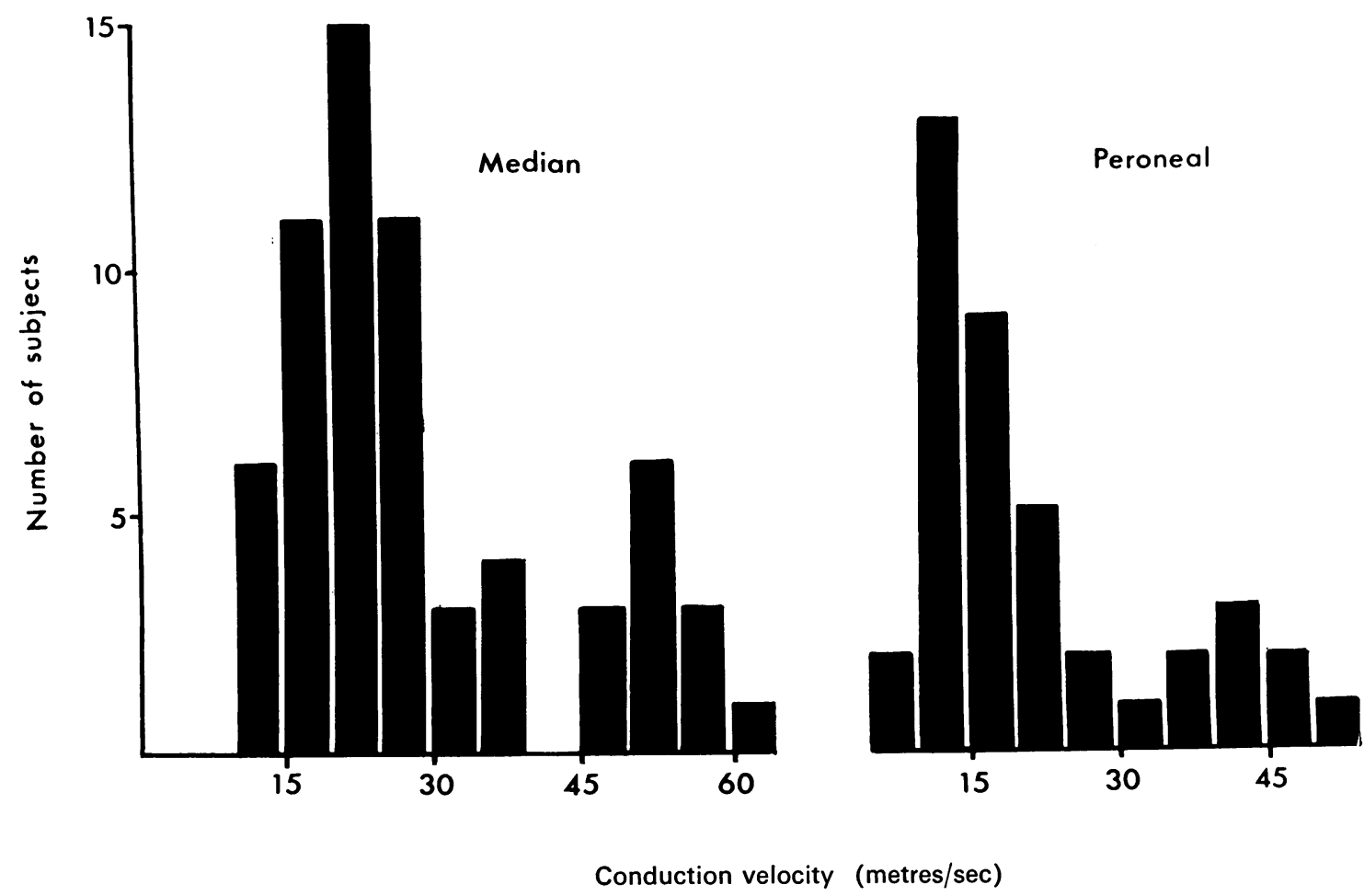

FIG. 1. Frequency distribution for motor nerve conduction velocity in the median and peroneal nerves in cases of peroneal muscular atrophy. 
was $32-35^{\circ} \mathrm{C}$. Sensory nerve conduction was also examined in the median and often the ulnar nerve, by the technique of Gilliatt and Sears (1958). All affected individuals showed abnormalities of sensory conduction, but this report will be confined to a consideration of motor nerve conduction velocity.

\section{RESULTS}

Observations were made on 20 families. Of 219 relatives seen, 63 were found on examination to be affected. The pedigrees suggested an autosomal dominant pattern of inheritance in 18 families and a possible autosomal recessive pattern in two. Nerve conduction was examined in 88 individuals. Abnormalities were confined to clinically affected individuals, although in a number of subjects the neurological signs were minimal. The ages of the propositi ranged from 10 to 58 years with a mean of 28 . For the clinically affected relatives in whom nerve con- duction was examined, the range was 9 to 73 years with a mean of 32 .

The results obtained for motor nerve conduction velocity in all affected individuals are shown in Fig. 1. The number of observations is less for the peroneal than for the median nerve, as in 25 individuals the extensor digitorum brevis muscles were totally denervated. The distribution for both nerves is bimodal. The majority of individuals display a substantially reduced conduction velocity with a modal value of 20-24 $\mathrm{m} / \mathrm{sec}$ for the median nerve and $10-14 \mathrm{~m} / \mathrm{sec}$ for the peroneal. However, in both nerves, a small proportion of individuals fall into a group in which conduction velocity is either within normal limits or only slightly reduced, the corresponding modal values being $50-54 \mathrm{~m} / \mathrm{sec}$ for the median nerve and $40-44 \mathrm{~m} / \mathrm{sec}$ for the peroneal.

The values for conduction velocity in the median nerve in the propositi have been plotted

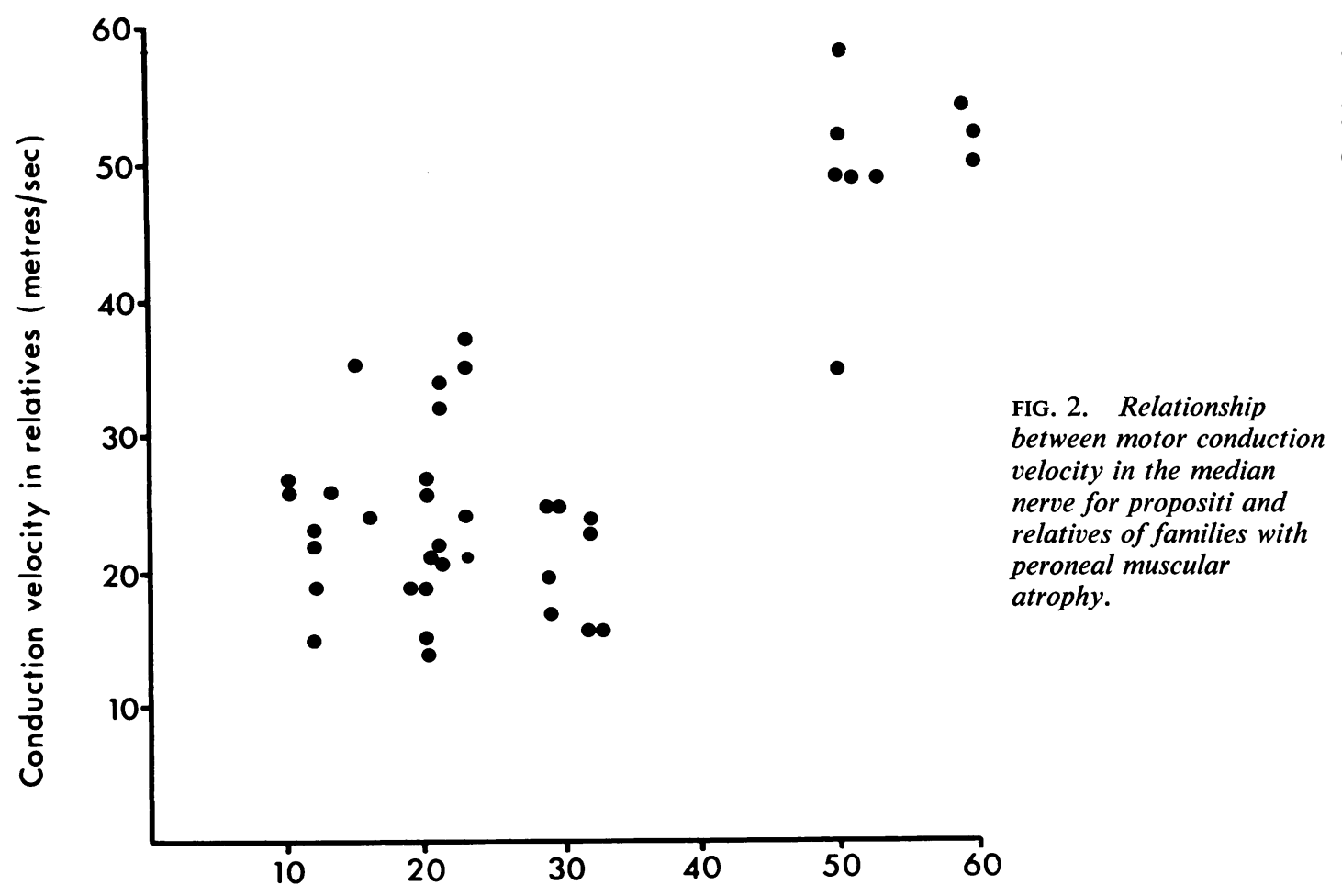

Conduction velocity in propositi (metres/sec) 


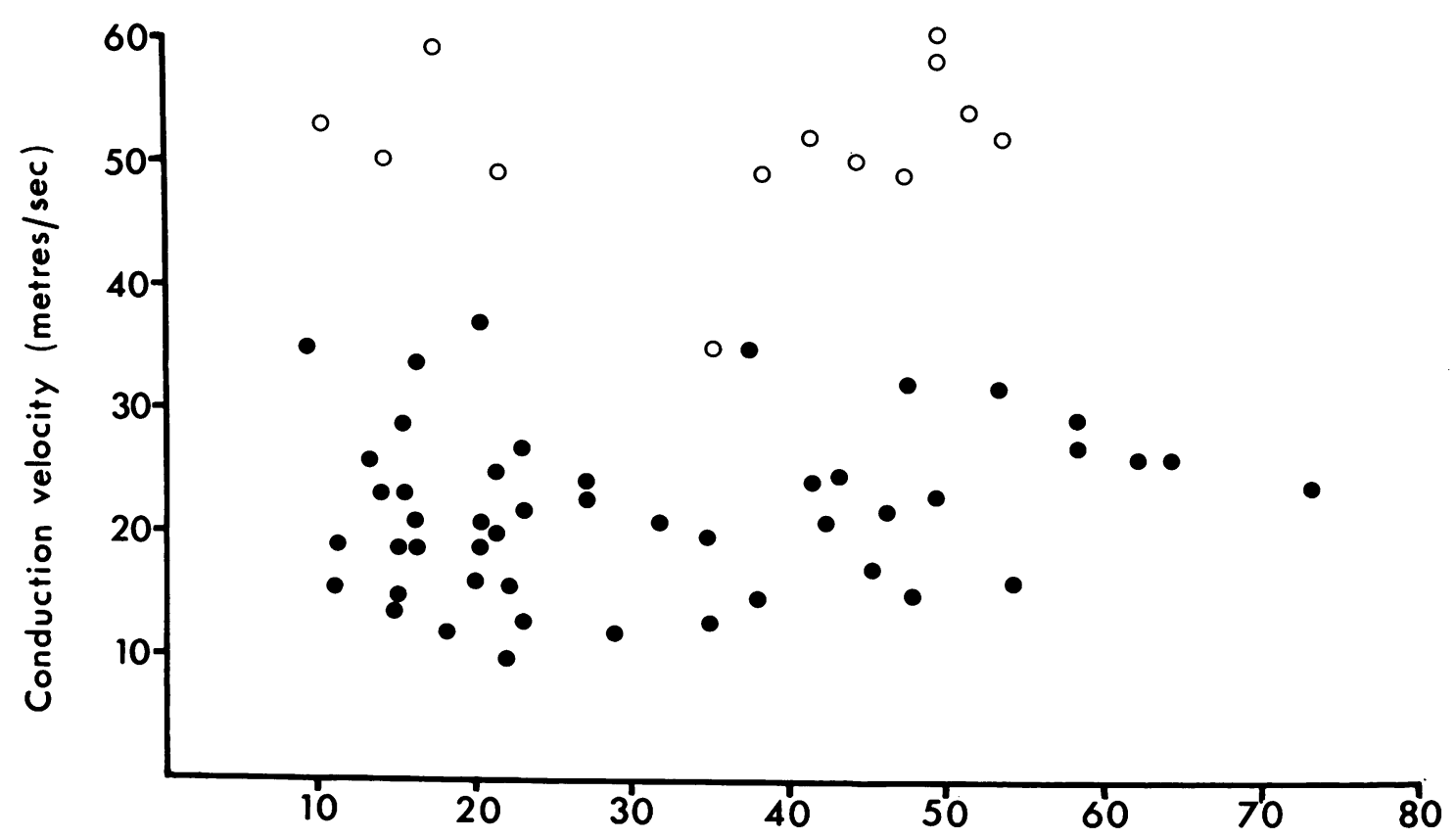

Age

FIG. 3. Relationship between motor conduction velocity in the median nerve and age (years) for patients with peroneal muscular atrophy. Cases from group I families. $\bigcirc$ Cases from group II families. For explanation, see text.

against those in the relatives in Fig. 2. The observations again fall into two groups, with a separation in the region of $40 \mathrm{~m} / \mathrm{sec}$ and there is only a trivial overlap between the two populations. This suggests that the bimodal distribution of values in Fig. 1 has a genetic basis. The present families have therefore been divided into two groups according to whether the values for the propositi are below (group I) or above (group II) $40 \mathrm{~m} / \mathrm{sec}$. A statistical analysis of the findings is given in the Table. The values for the peroneal nerve have not been analysed in this way, since they are considerably fewer in number, but a similar trend is evident.

The Table shows that there is a highly significant difference between the means for median nerve conduction velocity in the affected relatives of the two groups. Within each of the two groups, there is no significant difference $(P>0.05)$ between the mean values for the affected relatives in different families, nor is there any indication of a regression relationship between the means
TABLE

DESCRIPTIVE STATISTICS FOR MOTOR CONDUCTION VELOCITY IN MEDIAN NERVE IN AFFECTED INDIVIDUALS IN FAMILIES WITH PERONEAL MUSCULAR ATROPHY

\begin{tabular}{lcc}
\hline & $\begin{array}{c}\text { Mean } \pm S E \\
(\mathrm{~m} / \mathrm{sec})\end{array}$ & $S D$ \\
\hline Group I & & \\
$\quad$ Propositi & $19 \cdot 8 \pm 1 \cdot 6$ & $6 \cdot 5$ \\
Relatives & $22 \cdot 9 \pm 1 \cdot 1$ & $6 \cdot 4$ \\
& & \\
Group II & & \\
Propositi & $55 \cdot 5 \pm 2 \cdot 4$ & $4 \cdot 8$ \\
Relatives & $49 \cdot 8 \pm 2 \cdot 1$ & $6 \cdot 3$ \\
\hline
\end{tabular}

for the relatives and the values for the propositi. The values for the relatives in both groups appear to be clustered around a mean very similar to that of the propositi and the scatter about the mean is very similar to that of the propositi. The standard deviation of the propositi in group II is, of course, poorly determined, as it is based on only four values. 
No systematic attempt has been made to relate the values obtained for nerve conduction to the magnitude of the neurological deficit because of the difficulty in assessing the severity of the clinical involvement, but inspection of the data revealed no obvious correlation. The values for conduction velocity have been plotted against the age of the subjects for both group I and group II in Fig. 3. No correlation between conduction velocity and age is evident either in group I $(r=0 \cdot 17, \mathrm{P}>0 \cdot 1)$ or group II $(r=0.09$, $\mathrm{P}>0 \cdot 1)$.

\section{DISCUSSION}

This study has confirmed that in cases diagnosed clinically as peroneal muscular atrophy, motor nerve conduction velocity displays a bimodal distribution, being either relatively normal or else substantially reduced, with few intermediate values. The majority of cases have markedly reduced values and a smaller proportion of values that are either within normal limits or only slightly decreased. The separation into these two groups is likely to have a genetic basis, since relatives and propositi within both groups tend to display similar values.

The group with normal or only slightly reduced conduction velocity (group II) consisted of four families, in each of which the inheritance appeared to be of autosomal dominant pattern (Thomas et al., 1974). In the group with substantially reduced conduction velocity (group I), the inheritance appeared to be of autosomal dominant pattern in 14 families and was possibly of autosomal recessive inheritance in two. If this is so, group II is itself genetically heterogeneous. Moreover, an analysis of the clinical features of the families displaying dominant inheritance in this group (Thomas et al., 1974) suggested that they may also be genetically heterogeneous. Thus, although in the majority there is little sensory involvement, in some families extensive sensory loss develops, leading to neuropathic ulceration of the feet. It is of interest that, despite the clinical indication of genetic heterogeneity, there was no clear indication of differences in conduction velocity between the constituent families in group I. In the two families with possibly autosomal recessive inheritance, conduction velocity in the two affected sibs in each family was closely similar, being $19 \mathrm{~m} / \mathrm{sec}$ in the median nerve in both individuals in one family and 13 and $12 \mathrm{~m} / \mathrm{sec}$ in the other. These values are not as low as those recorded for recessively inherited polyneuropathy of Dejerine-Sottas type reported by Dyck and Lambert (1968a), where they were less than $5 \mathrm{~m} / \mathrm{sec}$. This supports the distinction made between the two conditions on clinical grounds.

Our results are comparable with those of Dyck and Lambert (1968a, b), but conflict in certain respects with the findings obtained by Amick and Lemmi (1963) and Myrianthopoulos et al. (1965). These authors reported individuals with reduced and with preserved conduction velocity in the same families. Myrianthopoulos et al. (1965) advanced the view that there is a spectrum of intergrading conditions which includes peroneal muscular atrophy, spinocerebellar degenerations, hereditary spastic paraplegia, and other disorders.

Dyck and Lambert $(1968 \mathrm{a}, \mathrm{b})$ recognized a separation into two groups similar to that obtained in the present study and also found that the values for nerve conduction velocity were consistent within families. In those cases with substantially reduced conduction velocity, nerve biopsies demonstrated extensive segmental demyelination and accompanying hypertrophic changes. They were therefore categorized as 'hypertrophic neuropathy of Charcot-MarieTooth type'. Nerve biopsies from similar families reported by Thomas et al. (1972) and Thomas et al. (1974), all of which are included in group I of the present study, have also demonstrated the same histological changes.

It has not yet been established whether the demyelination is of the primary type-that is, resulting from a disturbance of the myelin itself (or Schwann cell)-or whether it is secondary to an axonal disorder. Both of these mechanisms were suggested as possible explanations for the demyelination in hypertrophic neuropathy by Thomas and Lascelles (1967). Evidence has since been presented (Dyck et al., 1970) that, in recessively inherited hypertrophic neuropathy of Dejerine-Sottas type, the demyelination may be of the primary type. The explanation in the dominantly inherited disorders, and in the recessively inherited disorders where the clinical features correspond to those of peroneal muscu- 
lar atrophy, is unknown. In the five families with dominantly inherited Charcot-Marie-Tooth disease studied by Nielsen and Pilgaard (1972), the average values for motor and sensory conduction velocity in the median nerve were 23.6 and 19.8 $\mathrm{m} / \mathrm{sec}$ respectively. They concluded that as these values were similar to those normally found at birth, the pathological process is likely to involve an impaired post-natal myelination of nerve fibres. The occurrence of concentric Schwann cell proliferation, however, indicates that repeated demyelination and remyelination must occur.

The causation of secondary demyelination is so far uncertain. Thomas (1971) postulated that it might either be the consequence of a failure of the normal axonal mechanisms that are involved in instructing the Schwann cells to produce myelin, or that it could be the result of a progressive dwindling in the size of the axon so that demyelination occurs, the Schwann cell then readjusting to produce myelin with a thickness appropriate to the altered axon diameter. No supporting evidence for a progressive reduction in axon size has so far appeared. Measurements of motor nerve conduction velocity over periods of up to three years (Amick and Lemmi, 1963; Nielsen and Pilgaard, 1972) have shown no significant change, although this may be too short an interval for these very chronic disorders. Evidence against the axon progressively dwindling in size derives from the lack of any correlation between conduction velocity and age found in the present series. Nielsen and Pilgaard (1972), in fact, reported a positive correlation between conduction velocity and age. As emphasized by the latter authors, this is of interest as conduction velocity normally falls slightly with age (Wagman and Lesse, 1952). If conduction velocity does remain relatively unchanged throughout the course of the disorder, this would favour the operation of a limiting factor. It is possible that the process of myelination is faulty so that the nerve fibrethat is, axon/Schwann cell complex-is unable to maintain more than a certain reduced level of myelination.

In the group of cases in which conduction velocity is normal or only slightly reduced, Dyck and Lambert (1968b) considered that the pathological basis was likely to be a neuronal degeneration. A single nerve biopsy showed no demyelination or hypertrophic change. Such cases were termed the 'neuronal form of Charcot-Marie-Tooth disease'.

Full necropsy studies on peroneal muscular atrophy are few in number. Any cases in which hypertrophic changes were found at necropsy are likely in the past to have been designated as hypertrophic neuropathy and not as peroneal muscular atrophy. The postmortem reports will therefore be selected to include only those cases in which such changes were not present and they would thus fall into the present group II. The previous literature has recently been reviewed by Hughes and Brownell (1972) and they added four cases of their own. They discussed whether the process was a neuronal degeneration producing a primary loss of anterior horn and dorsal root ganglion cells, or a peripheral neuropathy in which there was an axonal degeneration that affected the peripheral portions of the axons in the first instance. On the basis of their own cases, they favoured the latter interpretation. While they observed loss of anterior horn and dorsal root ganglion cells, some of the anterior horn cells showed chromatolysis, which is not a feature of a primary neuronal degeneration such as motor neurone disease. Moreover, the maximal changes were observed in the peripheral nerves. They therefore believed that the process constituted a very chronic progressive peripheral neuropathy.

A patient examined in 1891 by Charcot died in 1958 at the age of 80 years. There were atypical features such that in later life she had developed unreactive pupils and bilateral optic atrophy. The necropsy findings were reported by Alajouanine et al. (1967). They described loss of anterior horn cells in the lumbar region and to a lesser extent in the cervical cord, but a single dorsal root ganglion appeared normal. The lumbar roots, particularly the posterior roots, showed a loss of myelinated axons and proliferation of endoneurial connective tissue, but no hypertrophic changes of onion-bulb type were seen. The peripheral nerves and muscles were not examined.

It is concluded from the present study that peroneal muscular atrophy, as diagnosed clinically, is genetically heterogeneous. Insufficient observations have as yet been amassed to enable statements to be made about possible differences 
in the natural history of the subtypes, but a recognition of the genetic variety is a necessary preliminary to the investigation of the underlying metabolic derangements. Terminology must remain difficult until the subtypes are better categorized.

In the majority of families (group I), the disorder consists of a hereditary polyneuropathy in which demyelination is known to be a prominent feature. This is consistently associated with hypertrophic changes in the nerves. Although Schwann cell proliferation of this type is just an epiphenomenon of a chronic demyelinating neuropathy, its arresting histological appearances have in the past led to the designation of cases in which these changes have been found as hypertrophic neuropathy. It therefore would be acceptable to classify the present group I families as the hypertrophic form of peroneal muscular atrophy until they can be identified more exactly by biochemical or other abnormalities. The degree of nerve thickening in these cases is never as gross as it may be in the childhood onset recessively inherited Dejerine-Sottas neuropathy. The nerves may not be enlarged on palpation, but nevertheless hypertrophic changes are consistently demonstrable in nerve biopsies.

The categorization of the group II cases poses greater difficulties. It is evident that the disorder in these families involves a disturbance of the lower motor and primary sensory neurones causing either a polyneuropathy of 'dying-back' type or a primary loss of these neurones. The pathological evidence, so far as it goes, favours the former interpretation. The values obtained for motor nerve conduction velocity indicate that segmental demyelination is likely to be absent or scanty. The designation of these cases as the 'neuronal' form of Charcot-Marie-Tooth disease (Dyck and Lambert, 1968b) is acceptable in the presen $i$ stage of knowledge providing that it is appreciated that it merely serves to draw attention to the salient pathological difference between the two groups-namely, the presence or absence of extensive demyelination, upon which the differences in conduction velocity presumably largely depend. It remains possible that the basis for the demyelination in the group I cases is a neuronal disturbance which at a later stage results in axonal destruction.
We wish to thank Dr. C. F. Elliott for assistance in the earlier stages of this investigation, Professor P. Armitage and Miss A. Petrie for advice and assistance with the statistical analyses, and Professor R. W. Gilliatt and Dr. Gregory Stewart for helpful discussion. Financial support from the Endowment Fund of the Royal Free Hospital and the Wellcome Trust is gratefully acknowledged. We also wish to thank Dr. Harold Edwards, Dr. R. S. Kocen, Dr. M. D. Rawson, Dr. G. M. Stern, and the surgeons of the Royal National Orthopaedic Hospital for referring cases.

\section{REFERENCES}

Alajouanine, T., Castaigne, P., Cambier, J., and Escourolle, R. (1967). Maladie de Charcot-Marie. Presse Médicale, 75, 2745-2750.

Amick, L. D., and Lemmi, H. (1963). Electromyographic studies in peroneal muscular atrophy. Archives of Neurology (Chicago), 9, 273-284.

Blom, S., Hagbarth, K.-E., and Lundberg, P. O. (1964). Motor conduction velocities in amyotrophic lateral sclerosis, polyradiculoneuritis and Charcot-Marie-Tooth's disease. Acta Neurologica Scandinavica, 40, 6-12.

Charcot, J.-M., and Marie, P. (1886). Sur une forme particulière d'atrophie musculaire progressive, souvent familiale, débutant par les pieds et les jambes, et atteignant plus tard les mains. Revue de Médecine, 6, 97-138.

Christie, B. G. B. (1961). Electrodiagnostic features of Charcot-Marie-Tooth disease. Proceedings of the Royal Society of Medicine, 54, 321-324.

Dejerine, J. (1896). Contribution à l'étude de la névrite interstitielle hypertrophique et progressive de l'enfance. Revue de Médecine, 16, 881-925.

Dejerine, J., and Sottas, J. (1893). Sur la névrite interstitielle, hypertrophique et progressive de l'enfance. Comptes Rendus de la Societé de Biologie, 45, 63-96.

Dyck, P. J., and Lambert, E. H. (1968a). Lower motor and primary sensory neuron diseases with peroneal muscular atrophy. 1. Neurologic, genetic, and electrophysiologic findings in hereditary polyneuropathies. Archives of Neurology (Chicago), 18, 603-618.

Dyck, P. J., and Lambert, E. H. (1968b). Lower motor and primary sensory neuron diseases with peroneal muscular atrophy. 2. Neurologic, genetic, and electrophysiologic findings in various neuronal degenerations. Archives of Neurology (Chicago), 18, 619-625.

Dyck, P. J., Lambert, E. H., and Mulder, D. W. (1963). Charcot-Marie-Tooth disease: nerve conduction and clinical studies of a large kinship. Neurology (Minneap.), 13, 1-11.

Dyck, P. J., Lambert, E. H., Sanders, K., and O'Brien, P. C. (1971). Severe hypomyelination and marked abnormality of conduction in Dejerine-Sottas hypertrophic neuropathy: myelin thickness and compound action potential of sural nerve in vitro. Mayo Clinic Proceedings, 46, 432-436.

Earl, W. C., and Johnson, E. W. (1963). Motor nerve conduction velocity in Charcot-Marie-Tooth disease. Archives of Physical Medicine, 44, 247-252.

England, A. C., and Denny-Brown, D. (1952). Severe sensory changes, and trophic disorder, in peroneal muscular atrophy (Charcot-Marie-Tooth type). Archives of Neurology and Psychiatry (Chicago), 67, 1-22. 
François, J., and Descamps, L. (1949). Étude neuro-ophtalmologique de deux souches d'amyotrophie neurale hérédodégénérative, l'une du type Charcot-Marie-Tooth (famille Joly), l'autre du type névrite hypertrophique de DéjerineSottas (famille Molle). Acta Neurologica et Psychiatric Belgica, 49, 648-676.

Gilliatt, R. W., and Sears, T. A. (1958). Sensory nerve action potentials in patients with peripheral nerve lesions. Journal of Neurology, Neurosurgery, and Psychiatry, 21, 109-118.

Gilliatt, R. W., and Thomas, P. K. (1957). Extreme slowing of nerve conduction in peroneal muscular atrophy. Annals of Physical Medicine, 4, 104-106.

Halliday, J. R., and Whiting, A. J. (1909). The peroneal type of muscular atrophy. With an accent of a family group of cases. British Medical Journal, 2, 1114-1118.

Henriksen, J. D. (1956). Conduction Velocity of Motor Nerves in Normal Subiects, and Patients with Neuromuscular Disorders. M.S. in Physical Medicine, Thesis: University of Minnesota.

Hughes, J. T., and Brownell, B. (1972). Pathology of peroneal muscular atrophy (Charcot-Marie-Tooth disease). Journal of Neurology, Neurosurgery, and Psychiatry, 35, 648-657.

Luban, B. (1952). Neurale Muskelatrophie und hypertrophische Neuritis. Klinischer bernischer und genealogischer Beitrag anhand einer bernischen Sippe. Schweizer Archiv für Neurologe und Psychiatrie, 68, 34-63.

Marinesco. G. (1894). Contribution à l'étude de l'amyotrophie Charcot-Marie. Archives de Médecine Experimentale et d'Anatomie Pathologique, 6, 921-965.

Myrianthopoulos, N. C., Lane, M. H., Silberberg, D. H., and Vincent, B. L. (1964). Nerve conduction and other studies in families with Charcot-Marie-Tooth disease. Brain, 87, 589-608.

Nielsen, V. K., and Pilgaard, S. (1972). On the pathogenesis of Charcot-Marie-Tooth disease. A study of the sensory and motor conduction velocity in the median nerve. Acta Orthopaedica Scandinavica, 43, 4-18.

Pette, H. (1936). Neurale Muskelatrophie. In Handbuch der Neurologie. Vol. 16, pp. 497-524. Edited by O. Bumke and O. Foerster. Springer: Berlin.

Roussy, G., and Lévy, G. (1926). Sept cas d'une maladie familiale particulière: troubles de la marche, pieds bots et aréfléxie tendineuse généralisée, avec, accessoirement, légère maladresse des mains. Revue Neurologique, 33, I, 427-450.

Roussy, G., and Lévy, G. (1934). A propos de la dystasie aréflexique héréditaire. Contribution à l'étude de la genèse des maladies familiales et de leur parenté entre elles. Revue Neurologique, 2, 763-773.

Thomas, P. K. (1971). The morphological basis for alterations in nerve conduction in peripheral neuropathy. Proceedings of the Royal Society of Medicine, 64, 295-298.

Thomas, P. K., and Calne, D. B. (1971). The classification of peroneal muscular atrophy and related disorders. In II International Congress on Muscle Diseases, Perth, Australia, 1971. Abstracts of paper presented. International Congress Series No. 237, 77. Excerpta Medica: Amsterdam.

Thomas, P. K., Calne, D. B., and King, R. H. M. (1972). Autosomal dominant forms of hereditary hypertrophic neuropathy. (Abstract.) Monographs in Human Genetics. Vol. 6, p. 210. Karger: Basel.

Thomas, P. K., Calne, D. B., Stewart, G., and King, R. H. M. (1974). Hereditary polyneuropathy of autosomal dominant inheritance. (To be published.)

Thomas, P. K., and Lascelles, R. G. (1967). Hypertrophic neuropathy. Quarterly Journal of Medicine, 36, 223-238.

Thomas, P. K., Sears, T. A., and Gilliatt, R. W. (1959). The range of conduction velocity in normal motor nerve fibres to the small muscles of the hand and foot. Journal of Neurology, Neurosurgery, and Psychiatry, 22, 175-181.

Tooth, H. H. (1886). The Peroneal Type of Progressive Muscular Atrophy. Lewis: London.

Tooth, H. H. (1887). Recent observations on progressive muscular atrophy. Brain, 10, 243-253.

Van Leeuwen, M. A. (1943). De la valeur des troubles pupillaires, en dehors de la syphilis, comme signe précoce ou forme fruste d'une affection hérédo-dégénerative. III. Une souche d'amyotrophie de Charcot-Marie-Tooth présentant des troubles pupillaires chez un grand nombre des ses membres et, chez l'un d'eux, des lésions typiques de névrites hypertrophique. Monatsschrift für Psychiatrie und Neurologie, 108, 1-89.

Wagman, I. H., and Lesse, H. (1952). Maximum conduction velocities of motor fibers in ulnar nerve in human subjects of various ages and sizes. Journal of Neurophysiology, 15, 235-244. 